\title{
Creación de la marca Seúl a través del Hallyu
}

\section{Creation of the Seoul Brand through Hallyu}

Recibido: 26/06/2020

Aceptado: 23/10/2020

Publicado: 30/11/2020
Julia Rodríguez Castillo

juliarodriguez@alu.uma.es

https://orcid.org/0000-0003-4379-9820

Universidad de Málaga (España)

Ana Almansa Martínez anaalmansa@uma.es https://orcid.org/0000-0003-0256-6369

Universidad de Málaga (España)

Resumen: Este artículo se centra en las propuestas de VisitSeoul.net, como parte de I.Seoul.U, para observar la marca de la capital surcoreana y entender cómo el Gobierno Metropolitano de Seúl ha desarrollado estrategias y actividades a través de su identidad e imagen. A partir de una revisión documental y una entrevista en profundidad a Lee Doo Ran (Ayuntamiento de Seúl) observaremos la importancia del Hallyu para la capital surcoreana y cómo este es aprovechado para ofrecer una experiencia más tradicional de la ciudad. Como veremos a lo largo del artículo, entender la convivencia entre lo moderno y lo tradicional es primordial para entender la personalidad de la Marca Seúl.

Palabras clave: Hallyu, K-Pop, Gobierno Metropolitano de Seúl, Marca ciudad, I.Seoul.U, VisitSeoul.net 
Abstract: This article focuses on the VisitSeoul.net activities, as part of I.Seoul.U brand, to observe South Korea capital's brand and understand how the Seoul Metropolitan Government has developed and develops different strategies and activities through its identity and image. From a documentary review and an in-depth interview with Lee Doo Ran (Seoul City Council), we observe the importance of Hallyu for the South Korean capital and how this is exploited as a claim for then offering the most traditional experience in the city. As we will see throughout this paper, we understand the coexistence between the modern aspects and the traditional aspects of the city is essential to understand the personality of the Seoul Brand.

Key words: Hallyu, K-Pop, Seoul Metropolitan Government, City Brand, I.Seoul.U, VisitSeoul.net

\section{Introducción: gobierno de Corea del Sur, Hallyu y K-Pop}

El objeto principal de este artículo es abordar la Marca Seúl, I.Seoul.U, a través del papel que se desempeña desde el Gobierno Metropolitano de Seúl (SMG). Para ello se realiza una revisión a los conceptos característicos que hay que tener en cuenta a la hora de crear y definir una marca ciudad y de concebir a Seúl como una capital multifacética en la que tanto lo moderno como tradicional tienen cabida: una ciudad abierta a diversos aspectos sociales, económicos y culturales centrados en el Hallyu (y más concretamente en el K-Pop), lo cual nos ayuda a entender el valor de los productos culturales locales a nivel global.

El gobierno de Corea del Sur ha participado activamente en actividades relacionadas con la promoción y el desarrollo cultural, sobre todo en la cultura pop, como destaca Dubravčíková (2018) sobre cómo este gobierno apoya la difusión de dicha cultura en el extranjero. No hay duda que Corea del Sur ha sabido aprovechar la oportunidad que ofrecen las industrias creativas para establecer puentes hacia un crecimiento no sólo cultural y económico, sino también como proceso de maduración necesario para definir la imagen y la personalidad del país. Para comprender este desarrollo, de manera global, es necesario comprender el Hallyu y su promoción por el gobierno de Corea como valor cultural y económico, con símbolos enriquecidos de valores intangibles. 
El Hallyu ("ola coreana") es un término que hace referencia a la expansión de la cultura pop coreana. El boom comenzó con la exportación de telenovelas o miniseries (conocidas como "K-dramas" o "doramas") a China a finales de los noventas (KOCIS, 2011 p. 11). Si bien en un comienzo, dichos programas se volvieron populares en países vecinos, la expansión superó los límites de Asia. En la actualidad, el Hallyu es un fenómeno global (Kelley, 2019), cuyas premisas originales han experimentado una revolución al ingresar a las redes sociales, configurándose el denominado "Hallyu 2.0".

Hallyu 2.0 es la combinación de las redes sociales, sus prácticas y los usos y posibilidades que ofrecen, y esta nueva etapa ha sido posible porque Corea ha avanzado sus tecnologías digitales. Al mapear el crecimiento de Hallyu 2.0, discutimos el papel del consumo impulsado por las redes sociales y los flujos de producción cultural en Asia y en todo el mundo en el contexto de las industrias creativas. (Jin, 2012)

Además, dicha revolución invitó a otros productos culturales a formar parte del juego. Lo que empezó como exportación de "K-dramas” " “K-pop” se expandió al mundo de la moda, el maquillaje, los videojuegos e incluso la gastronomía.

Este marketing global de la "K-Culture" ha mejorado aún más como parte de una política de impulsar la imagen nacional mediante la inversión en las industrias de infraestructura de banda ancha, en tecnología y en industrias del entretenimiento. Esto ha creado un entorno en el que la cultura pop podría florecer, resultando no sólo en el crecimiento económico sino también en impulsar las relaciones bilaterales y su aparente expansión. (Flew, 2016)

Dubravčíková (2018) señala que Corea del Sur ha promovido intensamente la cultura popular coreana para mejorar así la imagen y posición internacional del país. Una de las acciones que más beneficiaron esta ola cultural fue la creación, en el año 2008, del Ministerio de Cultura, Deportes y Turismo. Este ministerio realiza una labor esencial para el país en términos de notoriedad internacional, colocando al país dentro de la lista de "The Soft Power 30" (2018), donde se reconocen a los países con mayor índice de Soft Power.

De acuerdo con el mencionado ranking, la cultura es una fuente importante de "poder blando" en Corea del Sur. Asimismo, indica que la industria del 
entretenimiento surcoreana continúa creciendo globalmente, ganando reconocimiento por todo el mundo, registrándose puntajes sólidos en métricas “deportivas" y "turísticas" (Soft Power 30, 2018). Por lo tanto, y volviendo a Dubravčíková (2018), coincidimos en cómo Corea del Sur ha aprovechado el fenómeno Hallyu con resultados más que positivos.

Cabe destacar que el Ministerio de Cultura, Deportes y Turismo surcoreano creó un departamento específico para promover la globalización del K-Pop y, por ende, del turismo alrededor de este producto y actividad cultural (ET Bureau, 2019), clave en el desarrollo y expansión internacional de la marca-país.

Para comprender la importancia del K-Pop y el efecto que causa en el turismo, este artículo se centra en el grupo BTS (Bangtan Sonyeondan) y en el reporte de Hyundai Research Institute (2018), en el que se estima que aproximadamente 796000 extranjeros han visitado Corea del Sur por motivos relacionados con la banda BTS (desde su debut en 2013) y que las exportaciones totales concernientes al grupo se valoran en 1,26 trillones de wons (1,12 billones de dólares americanos). Como señala Moon-Hee (2018), mientras la popularidad de BTS se incrementaba, el total de turistas extranjeros ascendió en 0,45 puntos tres meses después; las exportaciones de ropa y accesorios aumentó en 0,18 puntos, los cosméticos en 0,72 y los productos relacionados con la alimentación coreana en 0,45 en el mismo mes.

Gracias a estos datos se puede determinar el valor considerable que BTS tiene para este país. Asimismo, el HRI (2018) comparte previsiones favorables (según las tendencias de éxito de este grupo) con relación al impacto en el turismo, la economía y las exportaciones. Así, se plasma cuantitativamente el valor que un grupo de K-Pop significa para Corea del Sur y nos ayuda a comprender la importancia de este producto cultural para el país, su impacto en países extranjeros (Hallyu y Soft Power) y su incidencia a la hora de crear una imagen de marca, a partir de sus productos culturales e inversiones en industrias creativas.

\section{Seúl: marca ciudad multifacética}

Las iniciativas que partieron desde el propio Seúl permitieron el éxito de los productos culturales de la ola coreana, beneficiando al movimiento K-Pop 
(BTS en este caso). En ese sentido, Soft Power 30 (2018) destaca la contratación de la mencionada banda (tras su victoria en los Billboard Music Awards 2017) por parte de la Organización de Turismo de Corea, para el lanzamiento de una canción promocional sobre Seúl. Tal fue el impacto de dicha noticia, que provocó el colapso de su web oficial, debido al gran tráfico de visitantes.

El artículo se enfoca en la banda juvenil BTS (como ejemplo más representativo del K-Pop) y en la ciudad de Seúl, como escenario social de oportunidades para tratar de comprender cómo gracias a dichas inversiones e iniciativas se pudieron configurar políticas de imagen de marca (país-territorio) y cómo este se comercializa a través de su cultura y (en concreto) a través del K-Pop.

Si bien Seúl es el epicentro de este fenómeno cultural, no hay olvidar que es una ciudad donde la tradición y el pasado se conservan, se respetan y son parte importante de su identidad: para entender la personalidad de esta ciudad hay que concebirla más allá del Hallyu y contemplarla como una capital multifacética.

Seúl, la capital y corazón de la República de Corea, es una ciudad antigua en la que su historia y tradiciones conviven con el mundo moderno, creando un escenario inusual. Desde una tecnología punta y una cultura que crea tendencia, hasta una historia y tradiciones notables, Seúl es una ciudad multifacética. En definitiva, se trata de una ciudad donde la innovación y la modernidad conviven con lo tradicional y lo antiguo. (SMG, 2017a)

El SMG es consciente que lidera una iniciativa con alcances multidisciplinares. Es por esto que pone en práctica diversas actividades y estrategias para (nutriéndose de las características mencionadas previamente) difundir y resaltar a Seúl como marca a través del "marketing de ciudades". Este último (también conocido como "marketing urbano") busca que las ciudades realicen una oferta adecuada a la demanda de sus diversos colectivos (ciudadanos, instituciones, turistas y visitantes) y que la estrategia se desarrolle de acuerdo con la identidad que singulariza cada ciudad, permitiendo su diferenciación (Muñiz \& Cervantes, 2010).

Desde el SMG se toma consciencia de la importancia del marketing turístico y del city marketing, no sólo por lo que entendemos como "turismo tradicio- 
nal", sino también por todo lo que englobaría el turismo de negocios (MICE) y el turismo relacionado con las industrias creativas. La creación de la marca país-territorio se basa en elementos diferenciadores y activos intangibles que poseen dichos territorios y que permiten un posicionamiento que contribuya al fortalecimiento de los siguientes aspectos:

- Incrementar la competitividad del territorio.

- Incrementar la atracción turística de un determinado lugar (ante ofertas cada vez más homogéneas en cuestión de servicios básicos, calidad y precio).

- Asegurar unos niveles de inversión extranjera, en peligro por el crecimiento del atractivo de territorios con economías emergentes.

- Obtener predisposición a consumir productos provenientes de una determinada región.

- Apoyar las exportaciones.

- Conseguir un determinado posicionamiento político territorial de carácter estratégico. (López \& Benlloch, 2005)

La imagen que se quiera proyectar debe ser un fiel reflejo de la identidad de la ciudad y no debe estar basada en conceptos de carácter abstracto, sino que debe caracterizarse por ser una oferta real y correspondiente a la marca referida. Valls (2013) entiende la "marca de destino" como identificador y representación de los productos, valores, sentimientos, experiencias y estilos de vida del territorio que representa, por lo que debe diferenciarse completamente de la competencia.

Algunas ciudades se convierten en marcas en sí mismas, en objetos de consumo a los que se viaja, en las que se quiere vivir, que ofrecen experiencias o monumentos que pueden llegar a ser iconos urbanos de consumo; destinos a los que muchas personas viajan o sueñan ir como experiencia vital. Hay ciudades que se han convertido en marcas de acuerdo con su identidad y estilos de vida; tal es el caso de grandes ciudades que forman parte de la cultura universal y están en el imaginario colectivo mundial, como Nueva York, París, Roma o Londres. (Muñiz \& Cervantes, 2010)

Dentro de este grupo de ciudades, se podría incluir a la capital surcoreana y destacar el Hallyu como una de las razones por las cuales Seúl es un atractivo 
turístico. Sin embargo, a pesar de que este artículo se ha centrado en las industrias creativas relacionadas con el Hallyu (como característica identitaria y diferenciadora que singulariza la ciudad de Seúl), se reitera la importancia de otros valores y activos (tangibles o intangibles) que perviven en la ciudad: el polifacetismo (tanto de las ofertas que ofrece la ciudad, como las demandas de los turistas) es condición sine qua non para entender la esencia y el carácter de esta marca-ciudad.

\section{La marca ciudad desde el SMG}

Para entender cómo el SMG plantea sus programas, actividades y estrategias (a fin de construir la imagen e identidad de la marca ciudad de la capital coreana, como parte de una campaña de branding asociada a la imagen-territorio) se requiere entender que el marketing de ciudades y el marketing turístico no se pueden desligar de la "marca-ciudad" o "marca-país" (Echeverri, 2013). La relación entre el "marketing territorial" y la "marca-país" se fundamenta en los siguientes factores:

- La internacionalización de las economías.

- El nuevo papel de los Estados y de las administraciones públicas en la promoción de la economía.

- La audiovisualización de la sociedad.

- La proliferación de nuevos productos.

De estas nace el objeto de esta investigación, centrado en este tipo de acciones desde una visión más gubernamental, otorgándose a la ciudad el rol de marca (Kotler et al., 2003). Se debe tener en cuenta que el branding impulsa con fuerza los productos y servicios de una marca, creando diferencias entre los productos (Kotler, et al., 2003), sin dejar de lado la imagen corporativa (Capriotti, 2013).

\section{Metodología}

Se propone el modelo de López \& Benlloch (2005) para realizar una aproximación al estado del concepto de marca-territorio y entender su importancia en cuanto a generación de valor añadido. Este modelo cuenta con cuatro fases 
de investigación: "exploratoria" (F1), "conclusiva" (F2), "contraste de datos" (F3) y "conclusiones finales" (F4), que renombraremos en este artículo como "valoración de resultados".

En la F1 se busca conocer el estado de la marca territorio que se va a investigar. De esta manera, se lleva a cabo una aproximación a los contenidos que ofrece la web del SMG (2019b) y así entender el estado actual de dicha marca y su proceso de creación. Con los datos obtenidos en esta fase se definen una serie de conclusiones (F2) que nos permiten contrastar la información recopilada en F1 con la obtenida en F3 y así conseguir la valoración de resultados (F4) que aportan una mayor comprensión sobre el estado de la marca Seúl.

El objetivo de la F3 es la comprobación de datos obtenidos en las dos fases anteriores con expertos o profesionales relacionados con la materia. En ese sentido, se llevó a cabo una entrevista en profundidad a Lee Doo Ran, manager de la Oficina de Turismo y Deportes, División de la Industria del Turismo del Ayuntamiento de Seúl. Del mismo modo, se indaga acerca de la marca Seúl a través del portal VisitSeoul.net, así como de la revisión documental de guías, folletos, programas de actividades, etc.

\section{Resultados}

\subsection{Fase exploratoria y fase conclusiva}

De la obtención de datos sobre el proceso de creación y el estudio de la marca se reafirma que la marca de la ciudad de Seúl nace como fruto de un elaborado plan de branding, donde la participación ciudadana fue un elemento clave para el resultado final, ya que permitió la creación de una marca fiel a la esencia de la ciudad. A diferencia de otros casos, el SMG (2019b) decidió invitar a los ciudadanos a integrarse y liderar el proyecto de branding de la ciudad desde su etapa inicial.

E1 SMG buscó crear una marca con el protagonismo de los ciudadanos, una marca que abrazara el pasado y el presente de Seúl, además de que fuera capaz de trasmitir la diversidad existente en la ciudad, que cobija "numerosas nacionalidades y generaciones, montañas y ríos, palacios antiguos y rasca- 
cielos, y todo tipo de elementos que coexisten en armonía" (SMG, 2019b). Según López \& Benlloch (2005), para crear una marca coherente e integrada, no deben existir diferencias entre la imagen real y la imagen percibida.

Tras recoger las opiniones de los ciudadanos, "convivencia", "pasión" y "relajación" fueron las palabras clave que reiteradamente aparecían para describir la identidad de Seúl (SMG, 2019a). En suma, se definía a la ciudad como "una ciudad relajada, llena de pasión".

- Pasión, la personalidad de la ciudad: cultura joven, moderna, aventurera.

- Coexistencia, la filosofía de la ciudad: fusión (tradicional y moderno, natural y urbano), multicultural, considerada.

- Relajación, el futuro de la ciudad: centrada en las personas, sostenible, eco-friendly.

En 2015 se establece la nueva marca de la capital coreana bajo el nombre I.Seoul.U ("City of me and you"), con un total de 84,348 participantes. Dicho número superó largamente al anterior concurso de proyecto de marca de la ciudad ("Hi Seoul", del 2002, con sólo 8,064 participantes). Cabe destacar que el proyecto fue ganador del premio Communication Design en 2016 por Red Dot Design Award.

En la web del SMG destacan "Visit Seoul”, "Seoul Solution”, "Seoul Global Center", "Invest Seoul” y "Mice Seoul” como páginas afiliadas y relacionadas con las actividades realizadas por el SMG. En realidad, la lista es mucho más extensa: en la Tabla 1 se observa el amplio listado de los sitios webs afiliados al SMG y englobados por la marca Seúl, lo cual grafica la gravidez y la multidisciplinariedad de este proyecto: se trata de 97 páginas afiliadas, de las cuales 25 pertenecen a los distritos de Seúl, así como una extensa red de oficinas gubernamentales y otros proyectos en paralelo. 
Tabla 1

Sitios webs afiliados al SMG

\begin{tabular}{|c|c|c|}
\hline CATEGORÍA & TÍTULO & TOTAL \\
\hline Distritos & $\begin{array}{l}\text { Gangnam-gu, Gangdong-gu, Gangbuk-gu, Gangseo-gu, Gwa- } \\
\text { nak-gu, Gwangjin-gu, Guro-gu, Geumcheon-gu, Nowon-gu, Do- } \\
\text { bong-gu, Dongdaemun-gu, Dongjak-gu, Mapo-gu, Seodaemun-gu, } \\
\text { Seocho-gu, Seongdong-gu, Seongbuk-gu, Songpa-gu, Yangcheon-gu, Yeong- } \\
\text { deungpo-gu, Yongsan-gu, Eunpyeong-gu, Jongno-gu, Jung-gu, Jungnang-gu. }\end{array}$ & 25 \\
\hline $\begin{array}{l}\text { Oficinas } \\
\text { afiliadas }\end{array}$ & $\begin{array}{l}\text { Hangang Project HeadquartersQuality Inspection Office, Seoul Metropolitan } \\
\text { Government, Public Health and Environment Research Institute, Seoul Water- } \\
\text { works Authority, Parks and Landscape Management Office, Seoul Metropolitan } \\
\text { Children's Hospital, Eunpyeong Hospital, Seoul Museum of Art, Seoul Human Re- } \\
\text { source Development Center, Seoul Museum of History, Sports Facilities Manage- } \\
\text { ment, University of Seoul, Seoul Emergency Operations Center, Seoul Data Center, } \\
\text { Seoul Historiography Institute, Seoul Child Welfare Center, Seoul Museum of Sci- } \\
\text { ence, Seobuk Hospital, Seoul Metropolitan Library, Agricultural Technology Cen- } \\
\text { ter, Officials' Recreation Center, Seoul Metropolitan Government, Seoul Grand } \\
\text { Park, TBS (Seoul Traffic Broadcasting System), } 119 \text { Special Rescue Services, Sew- } \\
\text { age Treatment Center, Seoul Metropolitan Government, Seoul Information Com- } \\
\text { munication Plaza, Digital Seoul, Public Service Reservation, Hanyangdoseoung } \\
\text { the seoul city Wall, Project Seoul, One Asia Pass, Fire \& Disatster Headquarters }\end{array}$ & 33 \\
\hline $\begin{array}{l}\text { Oficinas y } \\
\text { organismos } \\
\text { de } \\
\text { financiación } \\
\text { corporativa }\end{array}$ & $\begin{array}{l}\text { Invest Seoul, Visit Seoul, Mice Seoul, World e-Government Organization of Cities } \\
\text { and Local Governments, Dongdaemun Design Plaza, Seoul Legal Administrative } \\
\text { Services, Seoul Metro, Seoul Metropolitan Facilities Management Corporation, } \\
\text { Seoul Agro-Fisheries \& Food Corporation, SH Corporation, Seoul Institute, } \\
\text { Seoul Medical Center, Seoul Business Agency, Seoul Credit Guarantee Founda- } \\
\text { tion, Sejong Center for the Performing Arts, Seoul Women \& Family Founda- } \\
\text { tion, Seoul Arts and Culture Foundation, Seoul Welfare Foundation, Seoul Phil- } \\
\text { harmonic Orchestra, Seoul Volunteer Center, Seoul Design Foundation, Seoul } \\
\text { Scholarship Foundation, Seoul Global Center, SEOUL SOLUTION, The Future } \\
\text { City MAGOK, Citizens Hall, SETEC, DMC(Digital Media City), Sejong Story, } \\
\text { SeMA Nanji Residency, SEOUL BAEKJE MUSEUM, Seoul Welfare Foundation }\end{array}$ & 30 \\
\hline $\begin{array}{l}\text { Agencias } \\
\text { del } \\
\text { gobierno } \\
\text { central }\end{array}$ & $\begin{array}{l}\text { Government of the Republic of Korea, Ministry of Foreign Affairs, Min- } \\
\text { istry of Employment and Labor, Employment Permit System for For- } \\
\text { eigners, Ministry of the Interior And Safety, Ministry of Culture, Sports } \\
\text { and Tourism, Korea Immigration Service, Korea Tourism Organization }\end{array}$ & 9 \\
\hline & Total global & 97 \\
\hline
\end{tabular}

Nota: SMG (2019a).

\subsection{Contraste de datos: Oficina de Turismo y Deportes del Ayuntamiento de Seúl}

Al tratarse de una entrevista en profundidad, se trataron temas clave para entender la labor de este departamento. Uno de los temas destacados por Lee Doo Ran (la entrevistada) fue el Hallyu, destacando la iniciativa "Seoul Hallyu Activity Program", dirigida por su equipo de trabajo. Junto a este proyecto, se destaca "Oraegage". 
A pesar de contar con otros proyectos en marcha, los dos mencionados cobran importancia: el primero está más orientados hacia el Hallyu, las industrias creativas y sus productos culturales. En cambio, "Oraegage" busca preservar los espacios y establecimientos tradicionales de la ciudad.

\subsubsection{Seoul Hallyu Activity Program: la innovación}

Como se mencionó líneas arriba, este programa está asociado directamente a la imagen moderna de la ciudad. Asimismo, toma en consideración una serie de productos culturales que Visit Seoul engloba como parte del Hallyu:

- K-Pop.

- K-Drama \& Tv Show.

- K-Beauty.

- K-Food.

- E-Sport.

Lee Dooran (encargada de las propuestas enfocadas en el Hallyu) afirma que los contenidos más importantes de la lista son el K-Pop (tomándose como referencia el éxito del grupo BTS como generador de visitas y atracción turística). En segundo lugar, se colocan los K-Dramas \& TV Shows.

El Hallyu se reafirma nuevamente como un factor clave para el turismo y sirve precisamente para concatenar otros atractivos turísticos más convencionales y tradicionales que están englobados dentro del programa de Oraegage. Del mismo modo, se subraya el activismo de grupos como BTS, quienes tienen disponibilidad para colaborar con contenidos e iniciativas turísticas en beneficio de Seúl.

\subsubsection{Oraegage: la tradición}

Esta actividad está asociada directamente a la imagen tradicional de la ciudad. Se trata de un proyecto enfocado a preservar los locales y establecimientos (tiendas, restaurantes, etc.) más antiguos de la capital. En VisitSeoul. net (2018) se explica que 40 tiendas (ubicadas en los distritos de Jongo y Euljiro) fueron designadas como puntos de atracción por Oraegage, luego de 
ser sometidas a estrictos requerimientos (tener más de 30 años de antigüedad o tener una continuidad de administración familiar durante, al menos, dos generaciones).

El termino Oraegage está ligado directamente a los establecimientos que han continuado sus historia y tradición por un largo del tiempo en Seúl. El concepto nace de los mismos ciudadanos de la capital, que pretenden así expresar su deseo de que los establecimientos históricos se preserven a lo largo del tiempo. (SMG, 2017b)

\subsection{Valoración de resultados}

La convivencia entre la innovación y lo moderno, con lo tradicional y antiguo, es una de las características más notables de la capital coreana. Por un lado, como representación de la cultura innovadora (Seoul Hallyu Activity Program) y como representación del esfuerzo por preservar la tradición e historia (Oraegage). Ambos programas refuerzan la consolidación de una imagen territorial pluridisciplinaria, haciendo posible el encuentro del pasado con el presente.

Además, estos proyectos consiguen cumplir los objetivos establecidos por Lucero (2016), quien explica que el resultado de una "agenda de desarrollo de industria creativa", promovida sobre la demanda y necesidades de los actores.

Tabla 2

Objetivos de desarrollo de industria creativa

\begin{tabular}{|l|c|c|}
\hline \multicolumn{1}{|c|}{ OBJETIVOS } & SH & OR \\
\hline $\begin{array}{l}\text { Promover una mezcla de oferta cultural y comercial (industrias y } \\
\text { comercio cultural) más cercana a la realidad de la ciudad y a las } \\
\text { tendencias de los comportamientos ciudadanos. }\end{array}$ & $\mathbf{X}$ & $\mathbf{X}$ \\
\hline $\begin{array}{l}\text { Favorecer el desarrollo de actividades creativas y el asentamiento } \\
\text { de profesionales-organizaciones creativas que interactúan con la } \\
\text { ciudadanía, en marco del desarrollo de su propia actividad profe- } \\
\text { sional. }\end{array}$ & $\mathbf{X}$ & $\mathbf{X}$ \\
\hline $\begin{array}{l}\text { Favorecer la revitalización urbana, la generación de trama ciu- } \\
\text { dadana y vida cotidiana, potenciando las existentes (espacio Le } \\
\text { Parc, Galpón Ferroviario Parque Central, etc.), Pensado para } \\
\text { evitar el deterioro, reacondicionar los espacios y recrear las condi- } \\
\text { ciones de sostenibilidad demandadas. }\end{array}$ & & \\
\hline
\end{tabular}




\begin{tabular}{|l|c|c|}
\hline $\begin{array}{l}\text { Hacer más amable el acceso a los servicios culturales-creativos, } \\
\text { generando además una oferta dirigida a diversos sectores de } \\
\text { público, favoreciendo su socialización. }\end{array}$ & $\mathbf{X}$ & $\mathbf{X}$ \\
\hline $\begin{array}{l}\text { Ayudar a viabilizar la inversión cultural y su gasto corriente, que el } \\
\text { equipamiento creativo sea sostenible cultural, social y económi- } \\
\text { camente. }\end{array}$ & $\mathbf{X}$ & $\mathbf{X}$ \\
\hline
\end{tabular}

Nota: Elaboración propia a partir de Lucero (2016).

\section{Discusión y conclusiones}

La convivencia de lo moderno y lo tradicional nos ayuda a entender la esencial de Seúl, no sólo como ciudad, sino también como marca. Se trata de una dimensión tomada en cuenta para la creación de marca y que ha servido de guía en el desarrollo de proyectos afines. Entender la ciudad como una ciudad multifacética (donde el presente, el futuro y el pasado tienen la misma importancia) es esencial para comprender la personalidad, la imagen de marca y así alcanzar una marca-territorio fiel a la ciudad.

La orientación de las actividades que se desarrollan desde Visit Seoul tienen un enfoque fiel a esta imagen multifacética. Si se parte de los contenidos culturales derivados del Hallyu, la visita del turista es aprovechada para mostrar (además de dicha experiencia) su faz más tradicional. De esta manera, resulta interesante contemplar cómo el Hallyu se convierte en un elemento introductorio hacia la dimensión más tradicional de Seúl.

La estructura y alcances de la marca Seúl es amplia y está en constante crecimiento. Así, se destaca la aparición y popularidad de una marca coherente, global y fiel a la identidad de la ciudad.

Gnoth (2002) identifica la marca de destino como una marca paraguas que permite apalancar todo lo que se genera en su interior. Al igual que Papadopoulos \& Heslop (2002), entiende a la industria turística como un sistema en el que es necesario integrar las experiencias provistas por el destino y las experiencias provistas por sus productos $\mathrm{y}$ servicios. (Valls, 2013) 
Aparte de ser fiel a los intereses económicos, sociales y culturales de la ciudad, esta marca instala un "know-how" para crear "marca-territorio" y "marca-experiencia", planteados por los autores citados a lo largo de este artículo. Esto se complementa con el surgimiento de Corea del Sur como un país que explota su atractivo turístico mediante la activación efectiva de sus marcas-ciudades ("activos invisibles") paralelo a su éxito en el ámbito financiero e inversiones a nivel internacional.

Corea del Sur, a través de la experiencia con la marca Seúl, demuestra que la generación de percepciones positivas y alentar un mayor compromiso de la ciudadanía con los intereses del país provoca una mayor predisposición de las empresas y compañías a invertir, estimulando el apoyo público hacia los intereses del país, así como una mayor confiabilidad en la clase gobernando, considerándose a los políticos como verdaderos aliados de los intereses públicos (Woodier \& Park, 2017). Dichos beneficios concuerdan con los objetivos de I.Seoul.U, que ha logrado atraer anualmente a 20 millones de turistas extranjeros al año y entrar en el World's Top 3 Global MICE (SMG, 2019b).

\section{Fuentes consultadas}

Capriotti, P. (2013). Planificación estratégica de la imagen corporativa. IIRP-Instituto de Investigación en Relaciones Públicas.

Dubravčíková, K. (2018, Julio 18). K-POP as a global phenomenon. Why China fails to achieve similar success? https://ceias.eu/k-pop-as-aglobal-phenomenon

Echeverri, L. (2013, Julio 30). Marketing territorial y su relación con marca pais. https://paismarca.com/2013/07/30/marketing-territorial

ET Bureau. (2019, Julio 30). BTS tops Billboard 100 list: How K-pop helped Korea improve its economy. The Economic Times. https:// economictimes.indiatimes.com/magazines/panache/bts-tops-billboard-100-list-how-k-pop-helped-korea-improve-its-economy/articleshow/65266543.cms?from $=\mathrm{mdr}$ 
Flew, T. (2016). Entertaiment media, cultural power, and post-globalization: The case of China's international media expansion and the discourse of soft power. Global Media and China.

Gnoth, J. (2002). Leveraging export brands through a tourism destination brand. Journal of Management 9(4), 262-280. https://doi.org/10.1057/ palgrave.bm. 2540077

Hyundai Research Institute, HRI. (2018). Economic Effects of BTS. http:// www.hri.co.kr/board/reportView.asp

Jin, Y. (2012). Hallyu 2.0: The Korean wave in the age of social media. Nam Center for Korean Studies en International Institute (U-M).

Kelley, C. (2019, Enero 11). BTS lead the growth of Hallyu to nearly 90 million fans worldwide. Forbes. https://www.forbes.com/sites/caitlinkelley/2019/01/11/bts-lead-growth-of-hallyu-90-million-fans2018/\#7974ac1c70bc

Korean Culture and Information Service, KOCIS. (2011). The Korean Wave: A New Pop Culture Phenomenon. Korean Culture and Information Service Ministry of Culture, Sports and Tourism. Republic of Korea.

Kotler, P., Bowen, J., Makens, J., \& Moreno, R. (2003). Marketing para turismo. McGraw-Hill.

López, R., \& Benlloch, M. (2005). De la marca comercial a la marca territorio. RECERCA. Revista de Pensament i Anàlisi, 5, 87-100. http:// www.e-revistes.uji.es/index.php/recerca/article/view/239

Lucero, D. (2016). El turismo creativo. Una nueva estrategia de desarrollo local en el municipio de Godoy Cruz, provincia de Mendoza [Tesis de maestría]. Universidad Nacional de Quilmes, Argentina.

Moon-Hee, C. (2018). Economic Effects of BTS. K-pop Group BTS Induces Production Worth 4 Tril. Won per Year. Business Korea. http://www. businesskorea.co.kr/news/articleView.html?idxno=27583 
Muñiz, N., \& Cervantes, M. (2010). Marketing de ciudades y place branding. Pecunia. Revista de la Facultad de Ciencias Económicas y Empresariales, 1, 123-149.

Papadopoulos, N., \& Heslop, L. (2002). Country equity and country branding: Problems and prospects. Journal of Brand Management, 9, 294314. https://doi.org/10.1057/palgrave.bm.2540079

Seoul Metropolitan Government, SMG. (2017a). Official Tourist Guide 20172018. República de Corea.

Seoul Metropolitan Government, SMG. (2017b). Oreaegage Guide 20172018. República de Corea.

Seoul Metropolitan Government, SMG. (2019a). Family site. http://english. seoul.go.kr/family-site/

Seoul Metropolitan Government, SMG. (2019b). I.Seoul.U. http://english. seoul.go.kr/policy-information/culture-tourism/iseoulu/seoul/

Soft Power 30. (2018). The Soft Power 30: A Global Ranking of Soft Power 2018. https://softpower30.com/country/south-korea/

Valls, J. (2013). Planificación estratégica de destinos turísticos. Aspectos diferenciales por tipologías. Gestión estratégica sostenible de destinos turísticos. Universidad Internacional de Andalucía.

VisitSeoul.net (2018). Oraegage Part 1 - Seochon's Eateries. VISIT SEOUL. NET. http://english.visitseoul.net/tours/Oraegage-Part-1---Seochon's-Eateries_/24978?1etterSn=731\&ltcontent=180411_Oraegage+Part+1+-+Seochon's+Eateries

Woodier, J., \& Park, S. (2017). Republic of Korea: K-culture and the Next Wave of Economic Growth. International Journal of Cultural and Creative Industries, 5(1). http://www.ijcci.net/index.php?option=module\&lang $=$ en\&task $=$ pageinfo\&id $=249 \&$ index $=7$ 